\title{
Diversity of polyketide synthase (PKS) genes of eukaryotic algae in microbiomes of endemic Baikalian sponges
}

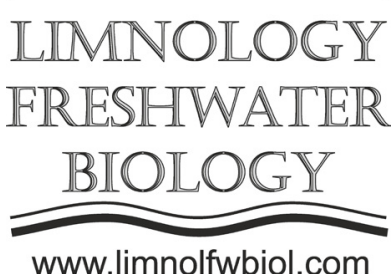

\author{
Kaluzhnaya O.V.
}

Limnological Institute, Siberian Branch of the Russian Academy of Sciences, Ulan-Batorskaya Str., 3, Irkutsk, 664033, Russia

\begin{abstract}
The present study focuses on identification and analysis of the diversity of polyketide synthase (PKS) genes of eukaryotic algae from the microbiomes of four species of Baikal sponges: Lubomirskia baicalensis, Baikalospongia fungiformis, Swartschewskia papyracea, and Rezinkovia echinata. PKS are multifunctional enzymes responsible for the synthesis of a wide variety of bioactive metabolites. All studied sponge communities contained the PKS-sequences closely related to those from the ochrophytic alga Nannochloropsis gaditana; in the microbiomes of three sponge species (except for S. papyracea) PKS-sequences with homology of haptophytic algae Emiliania huxleyi and Chrysochromulina sp. were revealed. The obtained data indicate that eukaryotic symbionts contribute, along with bacteria, to the formation of the biotechnological potential of the Baikalian sponges.
\end{abstract}

Keywords: Lake Baikal, endemic sponges, microbiome, eukaryotic algae, polyketide synthase

\section{Inrtoduction}

Symbiotic microorganisms of sponges (phylum Porifera) are noted as producers of biologically active secondary metabolites many of which have polyketide origin (Webster and Taylor, 2012). Polyketides are a wide class of low molecular weight natural products, the synthesis of which is carried out by multi-domain enzymes, polyketide synthases (PKS). It has been shown that bacteria from complex natural communities, including symbiotic communities of sponges, are the source of a large number of bioactive metabolites of pharmaceutical and industrial importance (Fischbach and Walsh, 2006). However, as recent studies show, eukaryotic algae may also synthesize a new biologically active substance (O'Neill, 2020). Among the eukaryotic symbionts of sponges, such groups as dinoflagellates, diatom, green, yellow-green, and red algae, are known (Webster and Taylor, 2012). The aim of this work was to identify the PKS genes of eukaryotic algae from the microbiomes of Baikal sponges and to determine the taxonomic affiliation of potential producers of biologically active substances, specific for communities of different sponge species.

\section{Materials and methods}

The study used freshwater sponges collected from a depth of 5-15 $\mathrm{m}$ in the lake. Baikal in different years: Lubomirskiabaicalensis (2010), Baikalospongia fungiformis
(2015) and Rezinkovia echinata (2015). Total DNA was isolated using the RiboSorb kit (Russia) according to the manual procedure. Amplification of the PKS gene fragment was performed using degenerate primers specific to the conserved region of the ketosynthase (KS) domain of PKS: DKF (5'-gtgccggtnccrtgngyytc-3 ') and DKR (5'-gcgatggayccncarcaryg-3'), after which the PCR fragments were cloned and sequenced (Kalyuzhnaya and Itskovich, 2016). The nucleotide sequences have been deposited in GenBank under the accession numbers: MT603533-MT603570.

\section{Results and discussion}

Eighty-one unique sequences of the KS domain PKS were identified in three microbiomes of the Baikalian sponges; of which 39 sequences belonged to eukaryotic microorganisms, as shown by BlastX analysis. In the community of L. baicalensis, 19 eukaryotic PKS were found; in the microbiome of $B$. fungiformis - 10; and in the $R$. echinata community - 10 sequences. Seven sequences from the $S$. papyracea microbiome, previously published by Kalyuzhnaya and Itskovich (2016) were also included in the analysis. Eukaryotic PKS from the Baikalian sponge communities were divided into two groups corresponding to eukaryotic algae's phyla Haptophyta and Ohrophyta. Twentytwo PKS sequences (10 from $L$. baicalensis, 3 from $B$. fungiformis, and 9 from R. echinata) belonged to phylum Haptophyta with two representatives: algae Emiliania 
huxleyi and Chrysochromulina sp. Twenty-four PKS sequences ( 9 from $L$. baicalensis, 7 from $B$. fungiformis, 1 from $R$. echinata, and 7 from $S$. papyracea) formed the phylum Ohrophyta, which is represented by the alga Nannochloropsis gaditana.

Phylum Haptophyta are predominantly phototrophic flagellates, widespread in the nannoplankton of marine and freshwater communities. One of the most common representatives of the phylum, Chrysochromulina parva, a psychrophylic stenothermal species, actively inhabited the communities of continental lakes, including Lake Baikal, were this species dominate over the years in the summer phytoplankton of (Izmest'eva, 2011). E. huxleyi, a unicellular shell alga, is the main fixer of carbonates in the oceans, playing an important role in the global biogeochemical equilibrium on Earth (Eikrem et al., 2016). Species of the genus Nannochloropsis are flagellate microalgae with a yellow-green chloroplast. Earlier, the species $N$. limnetica was found in Lake Baikal where its presence in phytoplankton samples was observed throughout the year (Fietz et al., 2005).

Thus, the composition of various Baikalian sponge's microbiomes contain ochrophytic and haptophytic algae that are potentially capable of producing bioactive metabolites. It is also noted that the different sponge microbiomes may contain the eukaryotic algae of the same taxonomic groups. We assume that the species of algae described above might be a part of the "core" community of endemic sponges of Lake Baikal.

\section{Acknowledgements}

The study was carried out with the financial support of RFBR and the Government of the Irkutsk region grant No. 20-44-380023 p_a.

\section{References}

Eikrem W., Medlin L.K., Henderiks J. et al. 2016. Haptophyta. In: Archibald J.M., Simpson A.G.B., Slamovits C.H. (Eds.), Handbook of the Protists. Cham: Springer, pp. 893-953. DOI: 10.1007/978-3-319-32669-6_38-1

Fietz S., Bleiß W., Hepperle D. et al. 2005. First record of Nannochloropsis limnetica (Eustigmatophyceae) in the autotrophic phytoplankton from Lake Baikal. Journal of Phycology 41: 780-790. DOI: 10.1111/j.1529-8817.2005.00112.x

Fischbach M.A., Walsh C.T. 2006. Assembly-line enzymology for polyketide and nonribosomal peptide antibiotics: logic, machinery, and mechanisms. Chemical Reviews 106: 3468-3496. DOI: 10.1021/cr0503097

Izmest'eva L.R. 2011. Long-term dynamics of Lake Baikal pelagic phytoplankton under climate change. Inland Water Biology 4: 301-307. DOI: 10.1134/S1995082911030102

Kalyuzhnaya O.V., Itskovich V.B. 2016. Distinctive features of the microbial diversity and the polyketide synthase genes spectrum in the community of the endemic Baikal sponge Swartschewskia papyracea. Russian Journal of Genetics 52: 38-48. DOI: 10.7868/S0016675816010094

O'Neill E. Mining natural product biosynthesis in eukaryotic algae. 2020. Marine Drugs 18. DOI: 10.3390/ md18020090 www.mdpi

Webster N.S., Taylor M.W. 2012. Marine sponges and their microbial symbionts: love and other relationships. Environmental Microbiology 14: 335-346. DOI: 10.1111/j.1462-2920.2011.02460.x 